\title{
Structural evolution under gamma ray irradiation of zircon originated
}

\section{from Hainan province, China}

\author{
Weidong Zhu ${ }^{1, \mathrm{a}}$, Long Fan ${ }^{1, \mathrm{~b}}$, Xirui Lu, $\mathrm{Lu}^{1, \mathrm{c}}$ \\ ${ }^{1}$ Fundamental Science on Nuclear Wastes and Environmental Safety Laboratory, Southwest \\ University of Science and Technology, Mianyang Sichuan 621010, P.R.China \\ a18380591007@163.com, bfanlong8804@163.com, 'Tuxiruimvp116@163.com
}

\begin{abstract}
Keywords: zircon, irradiation stability, Gamma ray, Raman spectroscopy, XRD.
Abstract:In order to investigate the structural evolution and the capability of resistance to $\gamma$-ray irradiation of natural minerals, the zircon from metamorphic rock in the middle region of Hainan was investigated. The morphologic characteristic of cracked rocks was observed and zircon crystals were selected under a multifunctional microscope. All the samples were irradiated using a ${ }^{60} \mathrm{Co}$ $\gamma$-ray source to $576 \mathrm{kGy}$. Phases and structures of the as-gained samples were characterized by X-ray diffraction (XRD) and Raman spectroscopy (Raman) before and after $\gamma$-ray irradiation. Moreover, the chemical compositions of zircons were analyzed by electron probe micro-analyser (EPMA) as well. The results show that the as-gained crystals which come from metamorphic rock undergone near 1483 million years geological evolvement and still contained $\mathrm{UO}_{2}$ and $\mathrm{ThO}_{2}$ with the contents of $0.3074 w t \%$. In addition, the samples had good crystallinity. No obvious damage to the structure is found in the zircon irradiated by $\gamma$-ray with $576 \mathrm{kGy}$, however the disorder degree of crystal has a slight increase.
\end{abstract}

\section{Introduction}

With the application of nuclear fission technology, nuclear waste production is always unavoidable. The treatment and disposal of nuclear waste have hence become the focus of nuclear industry [1-3]. Nowadays, numerous scholars consider that mineral crystal lattice immobilization is an excellent technique due to that it is convenient in handling, transportation, storage and disposal of the waste [4,5]. Ceramics (zirconolite and phosphate) are reliable matrices for the nuclear waste due to their excellent mechanical, thermal, chemical and radiation stability [6,7].

Zircon $\left(\mathrm{ZrSiO}_{4}\right)$ consists of triangular dodecahedral $\mathrm{ZrO}_{8}$ groups which form edge-sharing chains parallel to the $a$ - and $b$-axis, and $\mathrm{SiO}_{4}$ tetrahedral monomers which form edge-sharing chains with alternating $\mathrm{ZrO}_{8}$ groups parallel to the $c$-axis [8]. Natural zircon contains $\mathrm{U}$ and $\mathrm{Th}$ could to $5000 \mathrm{ppm}$, and it undergoes self-radiation damage via alpha decay over millions of years [9]. Zircon has long been recognized as a host material for the high-level nuclear waste (HLW), owing to the possibility of introducing large amounts of radionuclides into its crystal structure [10,11]. However, the final stability of the artificial waste forms could be guided a lot by the performance of natural minerals (such as zircon). Especially, the capability of resistance to irradiation will directly affect the final safety of the high-level radioactive waste. Therefore, the research of natural zircon is necessary [12].

In this article, zircons collected from the middle of Chinese Hainan (formed from about 1483 Ma [13]) were selected as investigative object. The chemical compositions of zircons were analyzed by electron probe micro-analyser (EPMA). All the samples were irradiated using a ${ }^{60} \mathrm{Co} \gamma$-ray 
source with $576 \mathrm{kGy}$ doses. Phases and structures of the as-gained samples before and after $\gamma$-ray irradiation were characterized by XRD and Raman.

\section{Experimental}

Metamorphic rocks (Biotite plagioclase gneiss) were collected from the eastern highway Changzheng farm of Hainan side of the quarry. Metamorphic rocks were broken, elutriated and choosing pure zircon crystals named WB. The samples irradiated using a ${ }^{60} \mathrm{Co} \gamma$-ray source with $576 \mathrm{kGy}$ doses were named FB. The $\gamma$-ray energy was $1.33 \mathrm{Mev}$, and the activity of radiation source was $150000 \mathrm{Ci}(5.55 \times 1015 \mathrm{~Bq})$.

The Laborlux 12 pol multi-functional microscope (Germany Leitz) was adopted to characterize the metamorphic rocks. The phase structures of sample WB and FB were characterized by an X-ray diffractometer (X'pert MPD Pro, Netherlands) with $\mathrm{Cu}$ K $\alpha$ radiation (The accelerating voltage of 40 $\mathrm{kV}$ ). Continuous scans were used for qualitative phase record in the $2 \theta=3^{\circ}$ to $80^{\circ}$ at a scanning rate of $25 \% \mathrm{~min}$. Electron probe micro-analyser (EPMA, JXA-8800R, Japan) was exploited to analyze the chemical compositions of zircons originating from natural rocks. The Raman spectra were recorded at room temperature using Invia Raman microscope system (Renishaw, UK). The $514.5 \mathrm{~nm}$ line from He-Ne laser was used as the excitation line. Laser power of $0.306 \mathrm{~mW}$ was focused to a spot of about $10 \mathrm{~lm}$ and a standard 50 objective lens was used for the collection of back-scattered Raman signal.

\section{Results and discussion}

The photos of samples under the multi-functional microscope are shown in Fig.1. It could be found that the mineral compositions mainly involve black mica, plagioclase, microcline, quartz, Zircon, apatite, magnetite and so on.
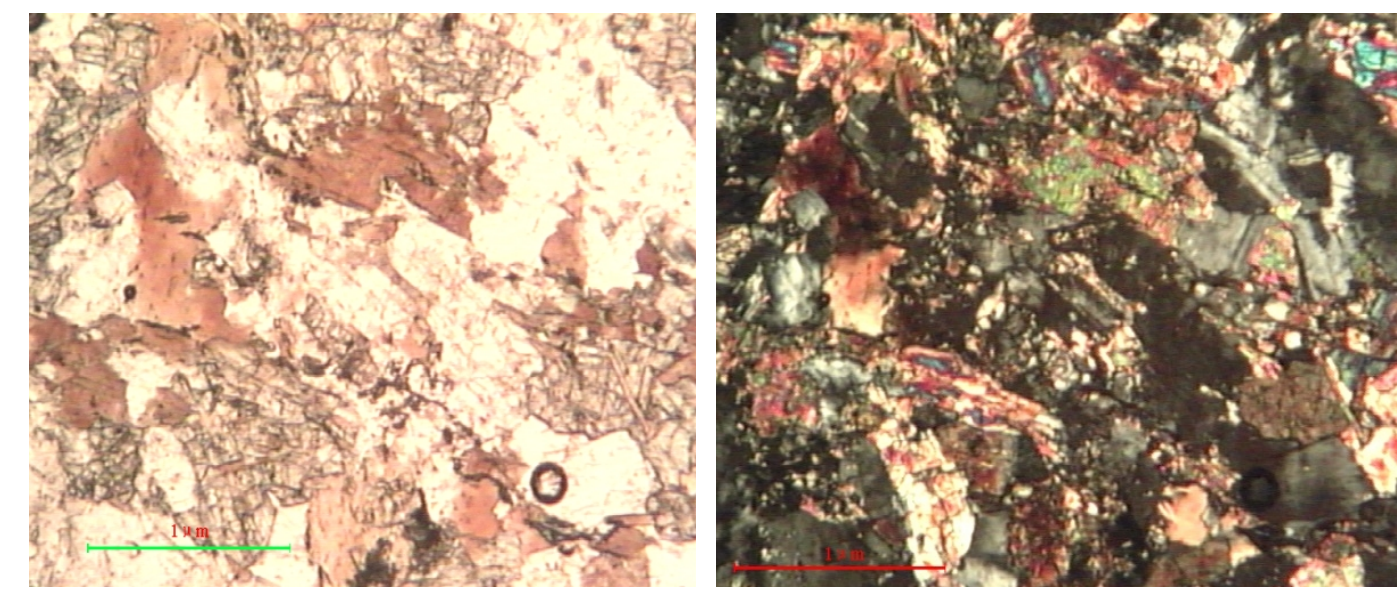

Fig.1. Images of sample metamorphic rock under a multi-functional microscope

The samples which were randomly chosen from WB were analyzed by EPMA and the results were shown in Tab.1. It can be observed that the relative contents of $\mathrm{ZrO}_{2}, \mathrm{SiO}_{2}, \mathrm{HfO}_{2}, \mathrm{Y}_{2} \mathrm{O}_{3}, \mathrm{UO}_{2}$, $\mathrm{ThO}_{2}$ and $\mathrm{PbO}_{2}$ are 64.8510, 32.3560, 1.3900, 0.0122, 0.2868, 0.0206 and $0.0074 w t \%$. Radioactive $\mathrm{UO}_{2}$ and $\mathrm{ThO}_{2}$ are important point of our attention. The as-gained crystals contain $\mathrm{UO}_{2}$ and $\mathrm{ThO}_{2}$ with the total contents of $0.3074 w t \%$, after $1483 \pm 13$ million years of geological evolution. 
Tab.1. Chemical composition of sample WB

\begin{tabular}{cccccccc}
\hline Station & $\mathrm{ZrO}_{2}$ & $\mathrm{SiO}_{2}$ & $\mathrm{HfO}_{2}$ & $\mathrm{Y}_{2} \mathrm{O}_{3}$ & $\mathrm{UO}_{2}$ & $\mathrm{ThO}_{2}$ & $\mathrm{PbO}_{2}$ \\
\hline $1-1$ & 64.83 & 32.20 & 0.56 & 0.1220 & 1.5410 & 0.0790 & 0.0161 \\
$1-2$ & 65.02 & 32.17 & 1.15 & 0.0000 & 0.0280 & 0.0030 & 0.0062 \\
$1-3$ & 64.60 & 32.59 & 1.01 & 0.0000 & 0.0520 & 0.0120 & 0.0028 \\
$2-1$ & 64.24 & 31.88 & 1.27 & 0.0000 & 0.1130 & 0.0050 & 0.0083 \\
$2-2$ & 65.29 & 31.81 & 1.44 & 0.0000 & 0.1890 & 0.0090 & 0.0064 \\
$2-3$ & 65.57 & 32.69 & 1.49 & 0.0000 & 0.3360 & 0.0150 & 0.0106 \\
$2-4$ & 64.17 & 32.38 & 1.82 & 0.0000 & 0.2860 & 0.0050 & 0.0096 \\
$3-1$ & 65.42 & 32.34 & 1.68 & 0.0000 & 0.1900 & 0.0580 & 0.0053 \\
$3-2$ & 64.65 & 32.79 & 1.77 & 0.0000 & 0.0920 & 0.0200 & 0.0049 \\
$3-3$ & 64.72 & 32.71 & 1.71 & 0.0000 & 0.0410 & 0.0000 & 0.0039 \\
Average & 64.8510 & 32.3560 & 1.3900 & 0.0122 & 0.2868 & 0.0206 & 0.0074 \\
\hline
\end{tabular}

Fig. 2 shows the powder XRD patterns of WB and FB. It can be seen from Fig. 2 that $\mathrm{ZrSiO}_{4}$ phase accounts for the major part in WB and FB. And characteristic peak is very sharp, which shows that the samples had good crystallinity. By comparing the two XRD patterns, it can be found that FB diffraction peaks exhibit a slight decline. This shows that the disorder degree of crystal FB sample has a slight increase.

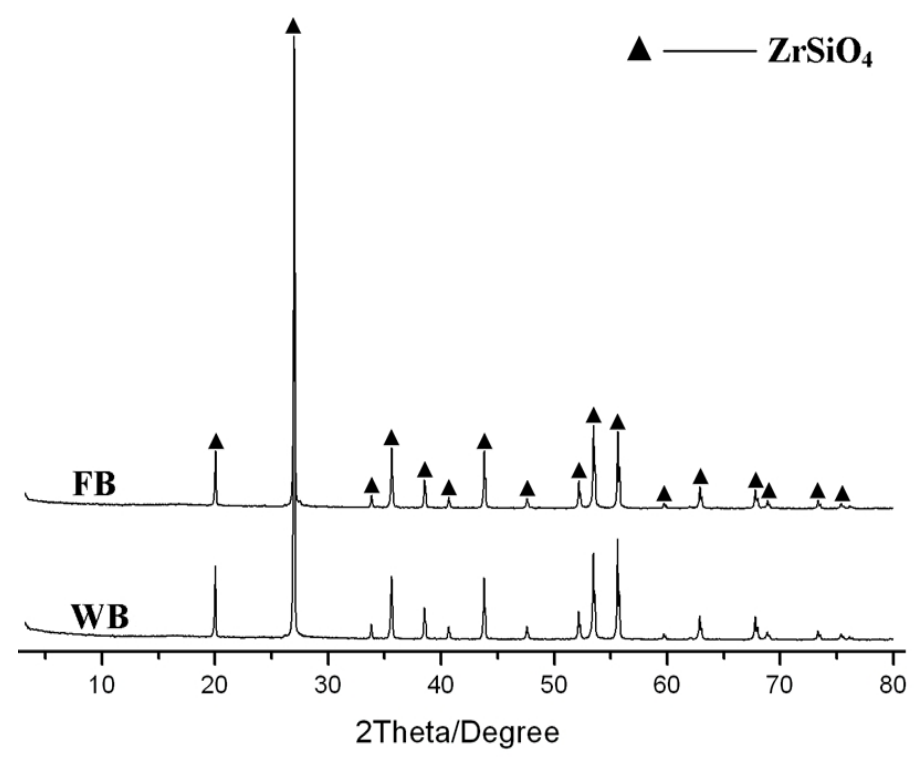

Fig.2. The XRD spectra of WB and FB samples

Fig. 3 shows the Raman spectra of WB and FB samples. It could be found that three dominant peaks arises at about 356, 439 and $1008 \mathrm{~cm}^{-1}$, these peaks are interpreted by Nasdala et al. [14] as representing the internal vibrations of $\mathrm{SiO}_{4}$ tetrahedra. The OMNIC software is used to fit the FWHM (W) with the most intense peak at $1008 \mathrm{~cm}^{-1}$, the results are shown in Tab.2. It can be 
observed from Tab.2 that the FWHM (W) of WB and FB samples are 7.84308 and 8.54955. The ratio of intensity of peak $(\mathrm{H})$ to FWHM (W) which is shown as H/W in Tab.2 decreases from 13847.2386 to 10680.8078 . This result demonstrates that the disordering degree of zircon induced by gamma ray irradiation is enhanced.

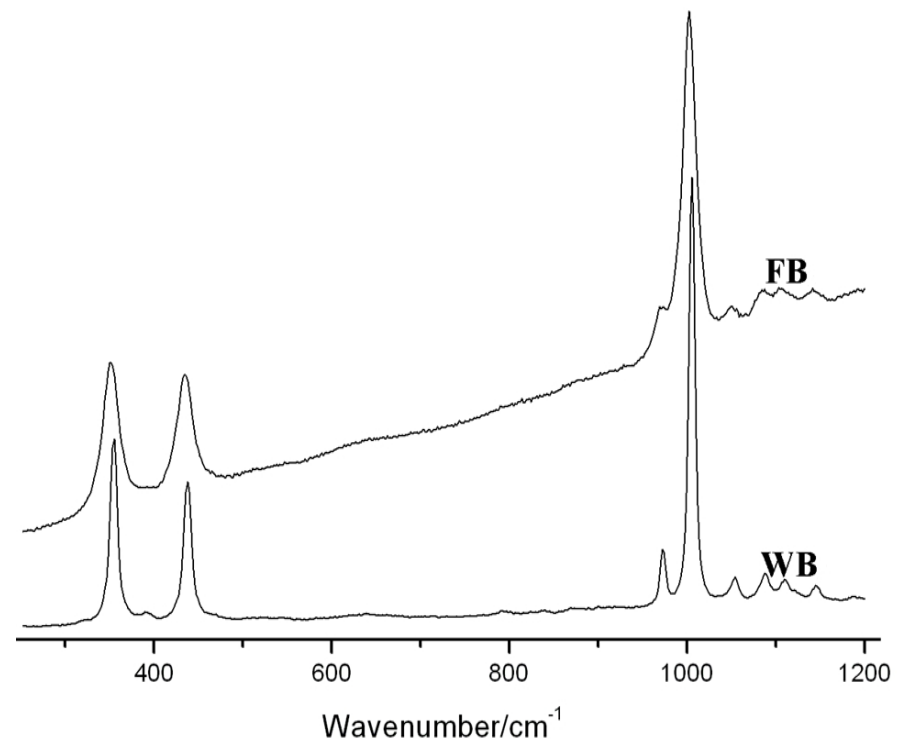

Fig.3. The Raman spectra of WB and FB samples

Tab.2. Calculated H/W of Raman spectrum near $1000^{-1}$ for samples

\begin{tabular}{ccccc}
\hline Sample & Station $/ \mathrm{cm}^{-1}$ & $\mathrm{H}$ & $\mathrm{W} / \mathrm{cm}^{-1}$ & $\mathrm{H} / \mathrm{W}$ \\
\hline WB & 1005.91 & 108605 & 7.84308 & 13847.2386 \\
FB & 1005.89 & 91316.1 & 8.54955 & 10680.8078 \\
\hline
\end{tabular}

\section{Conclusions}

In this study, zircons were successfully collected from the middle of Hainan province, China. The results show that the as-gained crystals which come from metamorphic rock undergone near 1483 million years geological evolvement and still contained $\mathrm{UO}_{2}$ and $\mathrm{ThO}_{2}$ with the contents of $0.3074 w t \%$, besides the samples had good crystallinity by the XRD analysis. The samples were irradiated using a ${ }^{60} \mathrm{Co} \gamma$-ray source with $576 \mathrm{kGy}$ doses. The disorder degree of irradiated sample has a slight increase from XRD and Raman analysis.

\section{Acknowledgements}

The authors would like to thank financial supports from Key Project of Sichuan Education Department (No. 14ZA0099), Foundation of Laboratory of National Defense Key Discipline for Nuclear Waste and Environmental Safety, Southwest University of Science and Technology (No. 13zxnk10).

\section{References}

[1] R C Ewing, W J Weber, F W Clinard Jr., Radiation effects in nuclearwaste forms for high-level radioactive waste, Progress in Nuclear Energy. 29 (1995) 63-127.

[2] H Kleykamp, Selection of materials as diluents for burning of plutonium fuels in nuclear 
reactors, Journal of Nuclear Materials. 275(1) (1999) 1-11.

[3] B P Mandal, N Garg, S M Sharma, et al., Solubility of $\mathrm{ThO}_{2}$ in $\mathrm{Gd}_{2} \mathrm{Zr}_{2} \mathrm{O}_{7}$ pyrochlore: XRD, SEM and Raman spectroscopic studies, Journal of Nuclear Materials, 392(1) (2009) 95-99.

[4] G Parcianello, E Bernardo, P Colombo, Low temperature synthesis of zircon from silicone resins and oxide nano-sized particles, Journal of the European Ceramic Society, 32(11) (2012) 2819-2824.

[5] H Tu, T Duan, Y Ding, et al., Preparation of zircon-matrix material for dealing with high-level radioactive waste with microwave, Materials Letters, 131(2014) 171-173.

[6] A Kaiser, M Lobert, $\mathrm{R}$ Telle, Thermal stability of zircon $\left(\mathrm{ZrSiO}_{4}\right)$, Journal of the European Ceramic Society, 28(11) (2008) 2199-2211.

[7] $\mathrm{N}$ Chanthima, J Kaewkhao, Investigation on radiation shielding parameters of bismuth borosilicate glass from $1 \mathrm{keV}$ to $100 \mathrm{GeV}$, Annals of Nuclear Energy, 55(2013) 23-28.

[8] M Taylor, R C Ewing, The crystal structures of the ThSiO4 polymorphs: huttonite and thorite, Acta Crystallographica Section B: Structural Crystallography and Crystal Chemistry, 34(4) (1978) 1074-1079.

[9] Y Ding, X Lu, H Tu, et al., Phase evolution and microstructure studies on $\mathrm{Nd}^{3+}$ and $\mathrm{Ce}^{4+}$ co-doped zircon ceramics, Journal of the European Ceramic Society, 35(7) (2015) 2153-2161.

[10]G Parcianello, E Bernardo, P Colombo, Low temperature synthesis of zircon from silicone resins and oxide nano-sized particles, Journal of the European Ceramic Society, 32(11) (2012) 2819-2824.

[11]P Trocellier, Chemical durability of high level nuclear waste forms, Annales de Chimie Science des Matériaux. No longer published by Elsevier, 26(2) (2001) 113-130.

[12]W J Weber, R C Ewing, A Meldrum, The kinetics of alpha-decay-induced amorphization in zircon and apatite containing weapons-grade plutonium or other actinides, Journal of Nuclear Materials, 250(2) (1997) 147-155.

[13]Y Zhang, R Zhang, N Hu, et al., High Grade Metamorphic Complexes in Middle Hainan Island: Ages of the $\mathrm{Pb}-\mathrm{Pb}$ Single Zircons and Their Geological Significance, Acta Geoscientica Sinica, 20(3) (1999) 284-288.

[14]L Nasdala, M Wenzel, G Vavra, et al., Metamictisation of natural zircon: accumulation versus thermal annealing of radioactivity-induced damage, Contributions to Mineralogy and Petrology, 141(2) (2001) 125-144. 